\title{
Syndromic multisystem autoimmune disease due to Itch deficiency
}

INSERM

\section{Source}

INSERM. (1999). Orphanet: an online rare disease and orphan drug data base. Syndromic multisystem autoimmune disease due to Itch deficiency. ORPHA:228426

Syndromic multisystem autoimmune disease due to Itch deficiency is a rare, genetic, systemic autoimmune disease characterized by failure to thrive, global developmental delay, distictive craniofacial dysmorphism (relative macrocephaly, dolichocephaly, frontal bossing, orbital proptosis, flattened midface with a prominent occiput, low, posteriorly rotated ears, micrognatia), hepato- and/or splenomegaly, and multisystemic autoimmune disease involving the lungs, liver, gut and/or thyroid gland. 